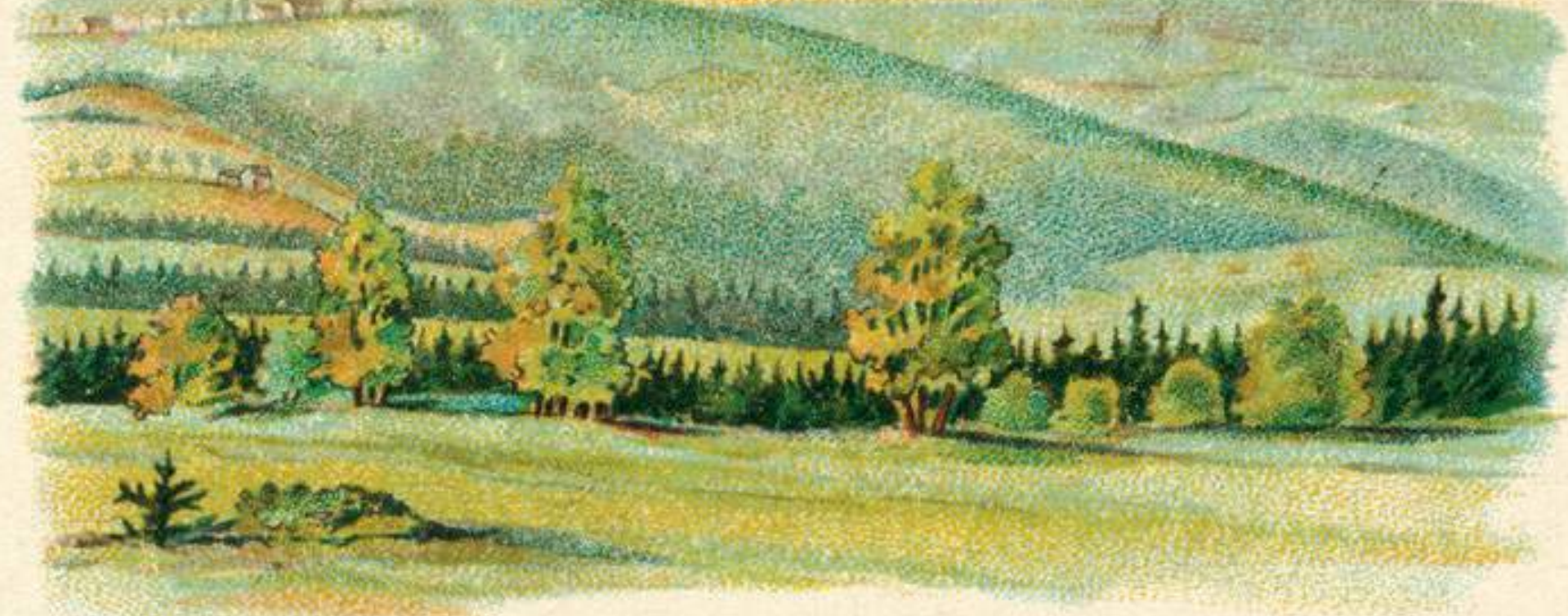

Seilferg m. Eonnenroirbel u. Lnrub $1245 \mathrm{~m}$.

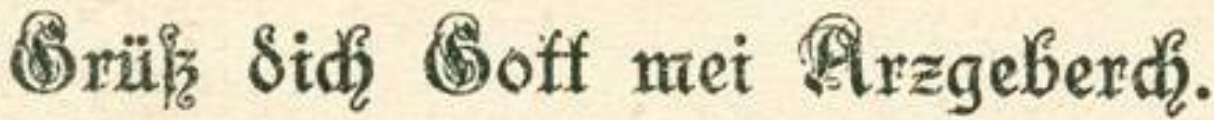

\section{Das erzgebirgische Mundartlied zwischen Tradition und Moderne}

\author{
Elvira Werner
}

Heimat -

Wort voll süßer Kinderträume Heimat -

schönste der Erinnerungen Heimat -

Vaterhaus und Mutterliebe Heimat -

ewig alt und ewig jung.

Stephan Dietrich (1898-1969), erzgebirgischer Mundartautor und Komponist
1 Es handelt sich bei dem hier abgedruckten Artikel um eine stark gekürzte Zusammenfassung einer umfassenden Studie der Autorin zum Thema „Erzgebirgisches Mundartlied“, welche sie bei Bedarf gern zur Verfügung stellt.
Die facettenreiche Musikkultur des Erzgebirges beeinflusste das sächsische Kultur- und Musikleben. Sie fand ihren Ausgangspunkt vor allem in den im 15./16. Jahrhundert gegründeten erzgebirgischen Bergstädten, die als frühe Zentren von Wirtschaft, Handel und Kultur mitteleuropäische Bedeutung erlangten. Daran erinnert in der „Montanregion Erzgebirge“ bis heute eine hohe Musikalität und ein breitgefächertes Musikschaffen - nicht zuletzt geprägt durch den Bergbau. Zum Fundament und den Spuren, die bis heute in die regionale Singpraxis und Instrumentalmusik führen, gehört das erzgebirgische Mundartlied, welches eng mit der im 19. Jahrhundert entstandenen Heimatdichtung verbunden ist.

Als eigenständige Liedkultur einer gelebten Alltags- und Heimaterfahrung hat das erzgebirgische Mundartlied in seiner Wandlung zum Gemeinschaftslied Anteil an der Folklorisierung des Erzgebirges im 20. Jahrhundert, wobei ein wesentlicher Impuls für die Entwicklung des erzgebirgischen Mundartliedes von Anton Günther (1876-1937) und seinem „Prototyp des erzgebirgischen Liedes“ ausging. Dass das erzgebirgische Mundartlied von den Erzgebirgern in der privaten wie öffentlichen Kulturpraxis bis heute gepflegt wird, spricht für seine Anerkennung im gesellschaftlichen Wertekanon, für dessen Einfluss auf den Heimatsinn, das Heimatbekenntnis der Akteure und für die integrative und homogenisierende Rolle gemeinsamen Singens und kultureller Aktivitäten überhaupt. Bis heute dient das erzgebirgische Mundartlied einer sprachlich-musikalischen, kulturellen und regionalen Identitätsfindung - nicht zuletzt findet es deshalb auch Beachtung in den Medien und für kommerzielle Zwecke. Langjährige Akteure unter den zahlreichen Solisten, Gesangs- und Instrumentalgruppen in einem nunmehr über einhundertjährigem Zeitraum der Mundartpflege, so 
z. B. das Erzgebirgsensemble Aue, welches seit 1962 existiert, wie auch unterschiedlichste Veranstaltungen innerhalb und außerhalb der Mundartregion und Sachsens, sprechen für diese ununterbrochenen Traditionspflege.

\section{Der Begriff „Heimat“ im Mundartlied}

Bereits um 1800 formte sich ein idealisierender, emotionaler Heimatbegriff, der durch das aufkommende Nationalbewusstsein im 19. Jahrhundert verstärkt wurde. Der Begriff „Heimat“ ist eng mit dem erzgebirgischen Mundartlied verknüpft. Bereits im Muster der Namensgebung erzgebirgischer Gesangsund Instrumentalgruppen verdeutlicht sich die regionale Bindung zum Heimatort, zur Bergbauregion oder zum Gründer. Von den über 100 Gruppen, die das Mundartlied pflegten, kann hier nur eine minimale Auswahl aus dem gesamten Zeitraum erwähnt werden. Ein wesentlicher Impuls für die Mundartpflege ging frühzeitig vom 1878 gegründeten Erzgebirgsverein e.V. und seinen damaligen Mitgliedern, die vorwiegend aus den Kreisen des mittelständischen Bürgertums entstammten, aus. Anfangs sang man hochdeutsche Erzgebirgslieder, wobei man später die mundartliche Lobpreisung der Heimat als etwas vertrautes, schönes und Erhaltenswertes empfand und verstärkt Mundartlieder in die Liederbücher des Vereins aufnahm und verbreitete. In den Liedern spiegeln sich oftmals die vielfältigen Veränderungen im Lebensalltag, wie beispielsweise in dem Lied „Wenn aaner ins Gebirg raufkimmt“ („Wenn einer ins Gebirge raufkommt") von Christian Friedrich Röder (1827-1900). Der Text entstand um 1890, wurde später vertont und das Lied wird bis heute gesungen. Das trifft ebenso für den vielzitierten, obererzgebirgischen „Sängerspruch von Röder“ (um 1901) zu: „Die alte Treu, gebirg'sche Art, bleibt immer neu von uns gewahrt." Das erzgebirgische Mundartlied besitzt dabei mit seinem Heimatverständnis eine soziale Dimension, die Verunsicherung, Verlusterfahrung oder Heimweh widerspiegelt und Heimat als wertebeständige Natur-, Sozial- und Kulturwelt versteht.

\section{Die Bedeutung des Mundartliedes im Erzgebirge}

Vor allem die Erzgebirgsregion trug entscheidend zur Industrialisierung Sachsens bei und beschleunigte die Urbanisierung. Gleichzeitig gewann die sogenannte „Lebensreformbewegung“, die sich mit ihrer Kritik an der Industrialisierung einer alternativen Lebenspraxis zuwandte und von Leitmotiven wie „Echtheit, Einfachheit, Ehrlichkeit, Verständlichkeit und Wahrheit“ geprägt wurde, zunehmend an Einfluss. In diesem Zusammenhang wurde die Volkskunde als Wissenschaft und die Heimatforschung im öffentlichen Bildungsalltag etabliert. Sie entwickelte sich besonders stark im Erzgebirge, wo sich viele heimatorientierte, bürgerliche Vereine gründeten. Im Zuge der Heimatbewegung zwischen 1871 und 1945 gewann dabei auch die Sprache als Heimatbezug an Bedeutung und rückte somit auch das Mundartlied in den Fokus.

Ursprünglich musizierte man das Mundartlied in privaten Stuben, was sich heute noch in den Texten wiederspiegelt: Der tradierte Begriff der erzgebirgischen „Hutzenstube/ Hutzenleute“ steckt noch in solchen Liedern wie „Hutzenmarsch/ Hutzenlied“. Der „Hutzenohmd“ („Hutzenabend“) etablierte sich als Veranstaltungsform hauptsächlich in der Advents- und Weihnachtszeit, in der auf den Weihnachtsmärkten im Erzgebirge das Mundartlied (z. B. „Heilig-Obnd-Lied“, „Wenn es Raachermannel naabel“, „Dr Schwarzenbarger Weihnachtsmarkt") bedingungslos dazu gehört. Glockenspiele wie das Chemnitzer (1936) und insbesondere das Lößnitzer Bronzeglockenspiel (1938) lassen bis heute, ausgehend von den beliebten Anton-Günther-Melodien, auch weitere erzgebirgische Mundartlieder erklingen. Die erzgebirgische Redensart „D(e)rham is d(e)rham“ („Daheim ist daheim“), welche 1895 als Liedtitel

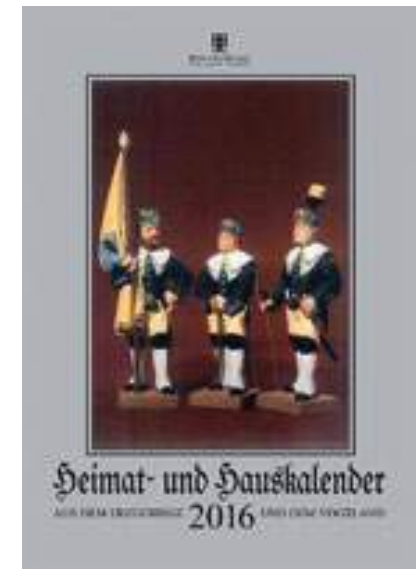

Heimat- und Hauskalender aus dem Erzgebirge, 2015
Liedpostkarte mit dem

Mundartlied „Drham is drham" von Anton Günther, um 1900

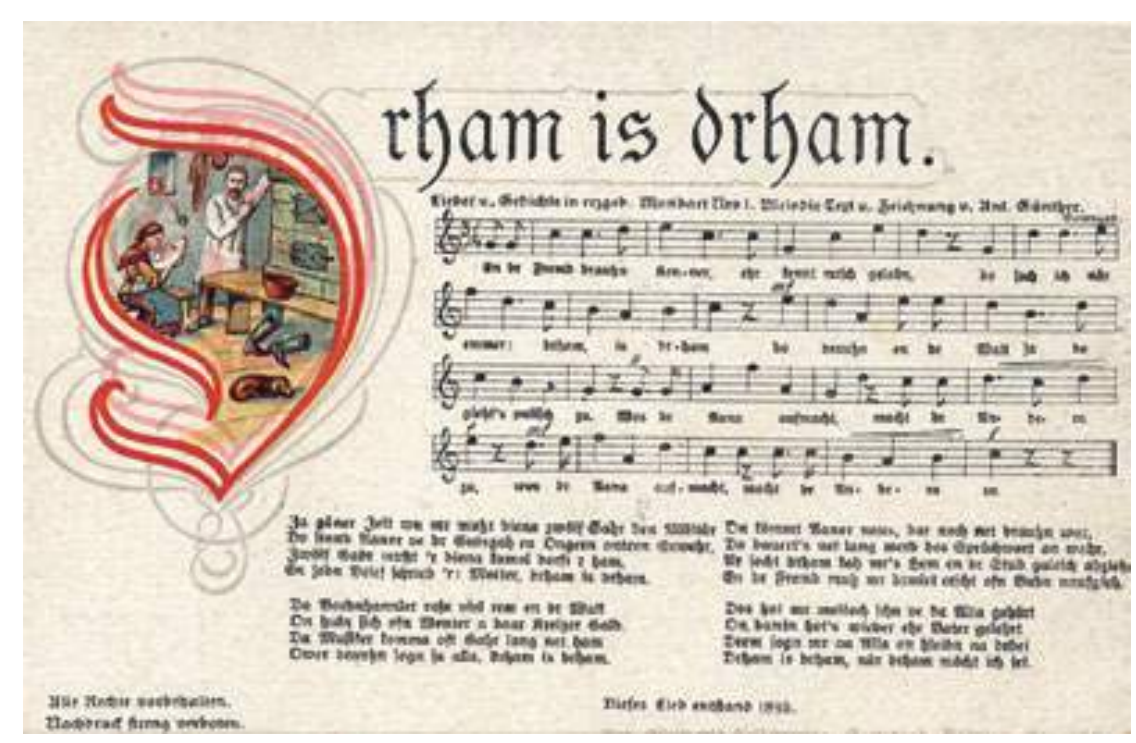




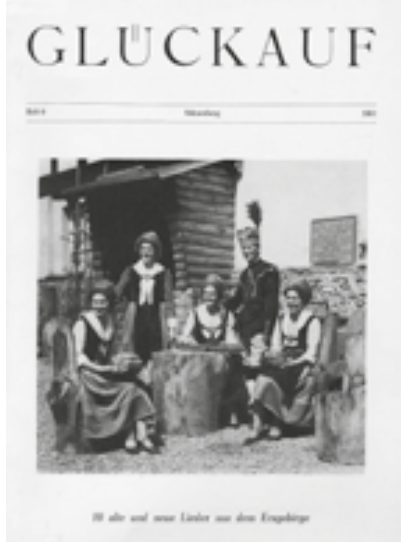

Liederbuch in der "Glückauf"-Reihe, 1981

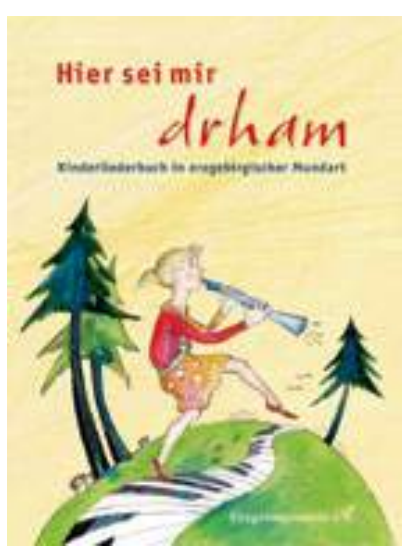

Kinderliederbuch herausgegeben vom Erzgebirgsverein e. V., 2013 für Anton Günther diente und nachfolgend von anderen Mundartautoren verwendet wurde, steht für einen Ort des Friedens, wo man mit der Welt im Einklang ist. Heute mehr als noch vor Jahrzehnten ist „Derham is derham“ als Schriftzug an Häusern in Erzgebirgsorten $\mathrm{zu}$ finden.

\section{Praktizierte Mundartliedpflege}

Eine dem erzgebirgischen Mundartlied und der von ihm geprägten Bezeichnung „Singendes Erzgebirge“ zuschreibende Erinnerungskultur veranlasst bis in die Gegenwart Erzgebirger älterer Generationen oder die, die in einer ihrer Lebensphasen mit dieser Liedkulturpflege in Kontakt kamen, sich auf unterschiedliche Art und Weise für seine Fortführung in der Kulturpraxis zu engagieren. Das erzgebirgische Mundartlied konnte so über viele Jahrzehnte bewahrt werden und wurde auch zum Ausgangspunkt für Variationen bis hin zu Bereichen wie „folk \& pop“ oder der volkstümlichen Stimmungs- und Unterhaltungsmusik. Dadurch glauben die Akteure der Mundartpflege das Schwinden von Mundarten und Dialekten aufzuschieben und zusätzlich zur Dokumentation alltagssprachlicher Zeugnisse beizutragen. Dabei dominiert die Mundart des Westerzgebirges, welche sprachgeschichtlich zum Obersächsischen gehört, das sich in 21 Dialekträumen und in acht regionale Obergruppen aufteilt. $^{2}$

Der Erzgebirgsverein e. V. trug wesentlich zur kulturtouristischen Förderung des Erzgebirges bei. Bis in die jüngste Gegenwart gehört zum Aufgabenspektrum des Erzgebirgsvereins die Pflege der Mundart (in Laienspiel, Literatur und Lied). Zahlreiche Zweigvereine und Veranstaltungen zeugen von der Begeisterung und Beständigkeit dieser Traditionspflege. In der Vereinszeitschrift „Glückauf“ werden regelmäßig aktuelle Liedpublikationen veröffentlicht. Daneben ist der Verein seit 1994 Ausrichter der jährlichen „Erzgebirgischen Jugendkulturtage“ und der seit 1995 aller zwei Jahre stattfindenden „Erzgebirgischen Mundarttage“. 2012 gab der Verein ein Kinderliederbuch in erzgebirgischer Mundart heraus.

\section{Zur Geschichte des erzgebirgischen Mundartliedes}

Es existiert eine Vielzahl von erzgebirgischen Mundartliedern. Erst im 19. Jahrhundert begann man mit der Niederschrift der
Kompositionen, deren Geschichte eng mit der Mundartdichtung verbunden ist. Die frühsten Überlieferungen stammen dabei vom Anfang des 19. Jahrhunderts. Christian Gottlob Wild (1785-1839) gilt als Begründer und Vater erzgebirgischer Mundartdichtung. Er publizierte um 1805 seine Erlebnisse bei Wanderungen im Erzgebirge und veröffentlichte 1816 in der Neuen Jugend-Zeitung eine erste kleine Lyrikanthologie „Vermischte Gedichte“. Beeindruckt von den „gutherzigen Erzgebirgern" schilderte und verklärte er in seinen authentischen Beschreibungen die erzgebirgische Kulturlandschaft und das Alltagsleben ihrer Bewohner. Einige seiner Gedichte wurden vertont und gehören bis heute zum Repertoire erzgebirgischer Gesang- und Instrumentalgruppen, wie z. B. „ $\ddot{A}$ annersch Weihnachtslied“, das Bergmannslied 's „A'fahrn“ bekannter unter dem Titel „Wenn’s Gelöckel dreie lett“, das „Wieng-Liedl“, „De Klippelmad“ und „Dr Gung mit dr Zither“. 1986 wurde Wild in seinem Geburtsort Johanngeorgenstadt ein Denkmal gesetzt und 1992 eine Straße nach ihm benannt. Zu den frühen Mundartlieder, das die Erzgebirgswelt harmonisiert, zählt auch das „Lied vom gebirgischen Maadel“ aus dem Jahr 1819 von Carl Friedrich Döhnel (1772-1853).

Großen Einfluss auf das Entstehen von Mundartliedern hatte das Erscheinen erster landschaftlicher Volksliederausgaben für das Erzgebirge, die oftmals vom Lehrerstand angeregt wurden. Die regionalen Liedsammlungen mit vorwiegend hochsprachlichen und auch mundartlichen Liedtexten („Tschumper-/Tschamperliedle“) wurden deshalb vor allem Schul- und Volksbibliotheken empfohlen. Gleichzeitig versuchte man damit die „Volkspoesie“ und Sangesfreude wieder lebendig zu machen und dem übermächtigen Einfluss der bis in die kleinste Dorfkneipe vordringenden Gassenhauer und Schlager entgegenzuwirken. Auch im Eigenverlag brachten einige Bürger Gedicht- und Liedsammlungen heraus, wie beispielsweise 1865 Friedrich Hermann Kleinhempel (18281883). Dafür diente auch die ab 1880 in Annaberg herausgegebene langjährige Reihe mit Gedichten und Geschichten in erzgebirgischer Mundart. Als erste Mundart-Autorin in dieser Reihe publizierte Anna Wechsler (1862-1922), die u. a. auch Lieder wie das dem Annaberger Volksfest gewidmete „KätLied" schrieb. Sie verfasste zudem Lieder in Verbindung mit ihren Theaterstücken: „In dr erzgebirg“schen Hutz'nstub“ bzw. „Dr Stern des Arzgebirgs“ („Der Stern des Erzgebir- 
ges“) nach der Melodie Anton Günthers's „Voterhaus“. Die Verwendung des Mundartliedes in Theaterdarbietungen begann um 1900, wo es vor allem in Rahmenprogrammen der Familien- und Vereinsabende des Erzgebirgsvereins e. V. zum Einsatz kam. Anfangs und bis in die 1930er Jahre erklangen Mundartlieder auch in den beliebten, aufkommenden Mundarttheaterstücken (Schwank bzw. Heimatspiel). Zahlreiche Zweigvereine pflegten zunehmend das mundartliche Theaterspiel in die anfangs, späterhin seltener, bekannte Mundartlieder eingebaut wurden. So z. B. 1905 zu einem erzgebirgischen Abend des Zwönitzer Erzgebirgszweigvereins mit einem Heimat-Festspiel „Heimkehr“ des Pfarrers und Heimatforschers Hermann Friedrich Löscher (18601944) in dem Anton Günther sang und musizierte, d. h. sich selber spielte. Dieses Stück handelte von der Bekehrung eines verloren geglaubten Sohnes, der ins Erzgebirge zurückkehrt. Im März 1937 spielte die Erzgebirgsbühne St. Joachimsthal für den Verein der Erzgebirgler in Prag das Stück „Mei Hamit“, die Anton Günther in seiner Originalrolle als „Dr Tolerhans-Tonl“ wiederum selbst darbot.

Auch die „Wandervogel“-Bewegung, die sich als eine der ersten Gruppierungen der bürgerlichen Jugendbewegung im Rahmen der Lebensreformbewegung um 1900 etablierte, bediente sich in ihren Liederbüchern des regionalen Liedgutes, darunter erzgebirgische Mundartlieder. So enthält z. B. die von einem Schuldirektor im osterzgebirgischen Olbernau herausgegebene Liedsammlung „Liederkranz für die deutsche Jugend“ einige Mundartlieder aus dem Erzgebirge und Vogtland.

Mundartlieder, wie das „Heiligobndlied“ („Heiligabendlied“, um 1836), „Mei Haamit läßt mich grüßen“ („Meine Heimat läßt mich grüßen“) aus dem Jahr 1886 von Hans Soph (1869-1954), „Derham is derham“ (1895), „Feierobnd“ (1903), „Hamwärts“ („Heimwärts") aus dem Jahr 1904 von Anton Günther (1876-1937) und „Dr Vugelbeerbaam“ (um 1887) von Max August Schreyer (18451922) gehören nach wie vor zum Repertoire kultureller Praxis. Das „Feierobnd-Lied“, welches 1903 bereits in Schlagerchroniken auftrat, ist bis heute ein beliebter Abschlussakt vieler regionaler Veranstaltungen und ein vielgesungenes Abschieds- und Begräbnislied und sein Text schmückt so manche Traueranzeige. Außerdem wurde es überregional rezipiert und variiert, z. B. in der Oberharzer Mundart (1994) und in Kölsch. Vom „Fei-
erobnd-Lied“ leitete sich zudem die in der NS-Zeit geprägte Bezeichnung „Erzgebirgische Feierabendkunst“ ab. Ende der 1980er Jahre entstand sogar eine anonyme umweltkritische Textvariante frei nach Anton Günther „Wu de Walder haamlich rauschen“ (,Wo die Wälder heimlich rauschen“), „Of de Barch is net mehr lustig [...] S‘ Wosser wor mal klor un kiesich, itza stinkt's un is ganz graa, un da Luft is schlacht un diesich, kimmt das böhmsche Giftgas raa.[...]“ („Auf den Bergen ist es nicht mehr lustig [...]. Das Wasser war mal klar und blaß, jetzt stinkt`s und ist ganz grau, und die Luft ist schlecht und diesig, kommt das böhmisches Giftgas an. [...]".3

Man kann heute drei musikalische Formen unterscheiden: 1. tradiertes Liedgut, welches mehr oder weniger neu interpretiert wird (u. a. „Bergsänger Geyer“, „Schwarzwasserperlen“, „De Holzmauser“, „De Zupf'r“, Heiner Stephani und Annett Illig), 2. das neue erzgebirgische Mundartlied, welches musikalisch von unterschiedlichsten modernen Musikstilen beeinflusst und im Wesentlichen dem Folk-Rock/FolkBlues zugeordnet werden kann und auch zeitgemäße, sozialkritische Texte beinhaltet und sich bewußt von der Tradition abgrenzt oder diese erweitert (u. a. Stefan Gerlach mit „Wind, Sand und Sterne“, „Schluckauf“, „Krippelkiefern“ und „Kendy John Kretzschmar") und 3. inszenierte, harmonisierenden volkstümliche Stimmungsmusik, die u. a. eine „Holzmichel-Renaissance“ einleitete (u. a. „De Randfichten“, „De Hutzenbossen“ und „De Stöckwurzeln“).

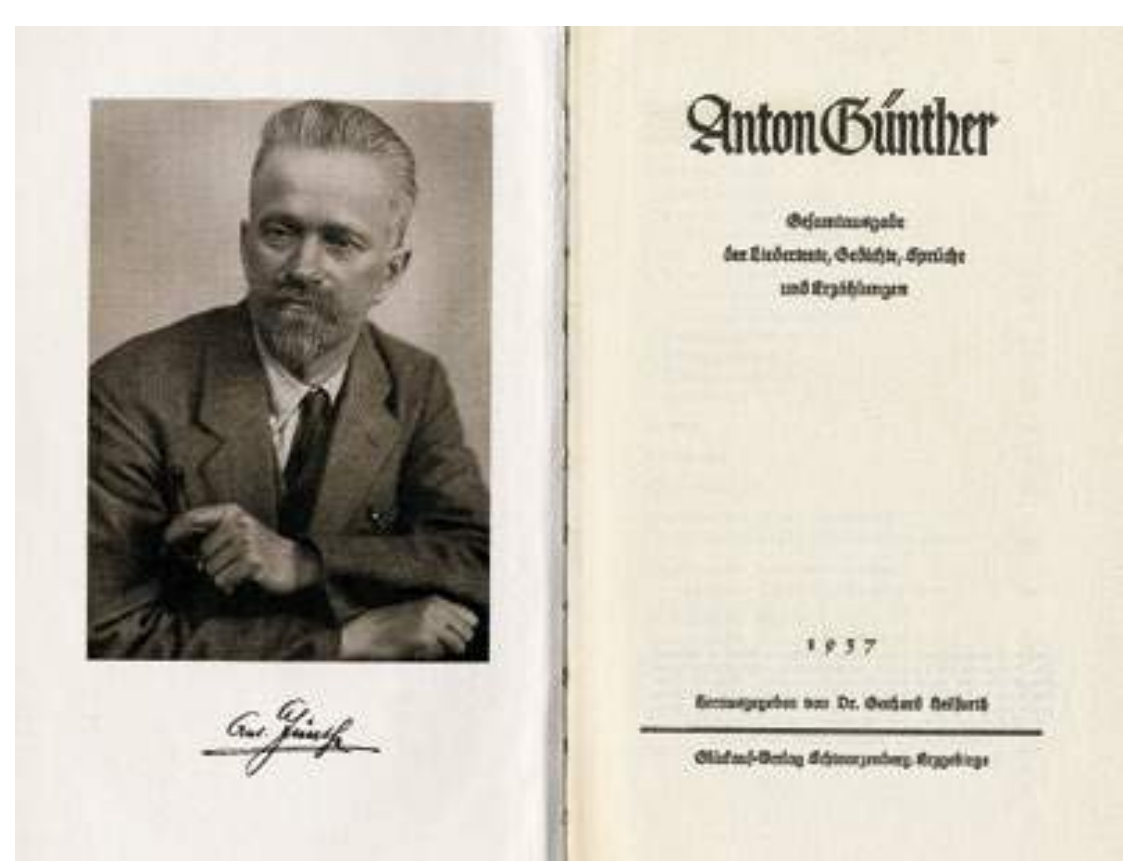

Frühe Gesamtausgabe von Werken Anton Günthers, herausgegeben von Gerhard Heilfurth, 1937 
Anton Günther in den 1930er Jahren

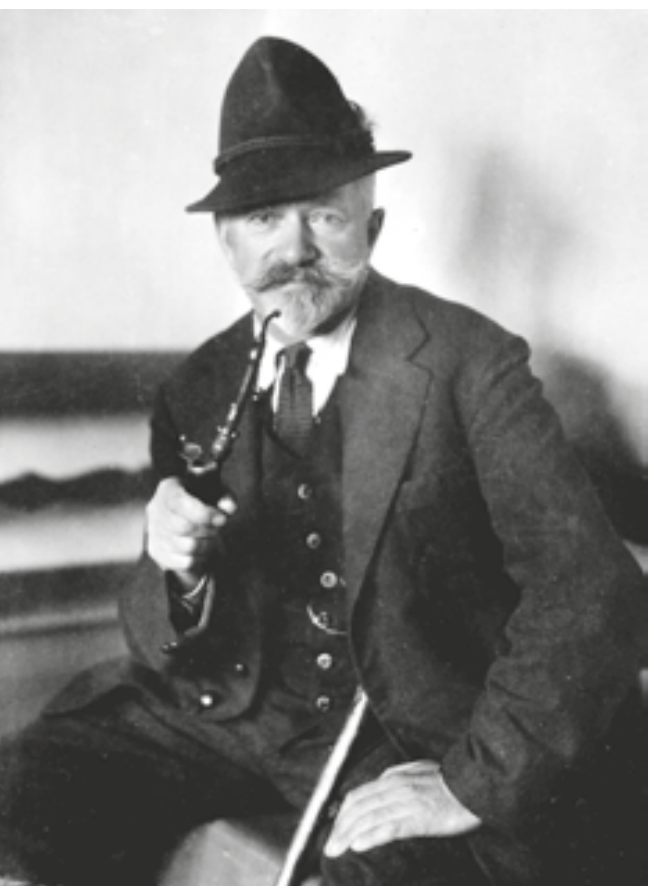

\section{Anton Günther (1876-1937) -} „Vater des Erzgebirges“

Dem Volkssänger und Liedermacher Anton Günther, Autodidakt und schon zu Lebzeiten als „Meistersinger des Erzgebirges“ wahrgenommen, kam eine stilprägende Rolle zu. Aufgewachsen in einer über Generationen hinweg von musikalischen Traditionen gezeichneten Familie reflektierte er, ausgehend von seinem sudetendeutschen wie familiären Lebensschicksal inmitten einer konfliktbeladenen Umbruchszeit, in seinen Liedern nicht allein sein persönliches Schicksal, sondern traf das Lebensgefühl und den Heimatsinn vieler Menschen in dieser Zeit, die durch die Erfahrungen des Ersten Weltkrieges traumatisiert waren. Durch die Gründung der Tschechoslowakischen Republik 1918 beklagten viele Erzge-

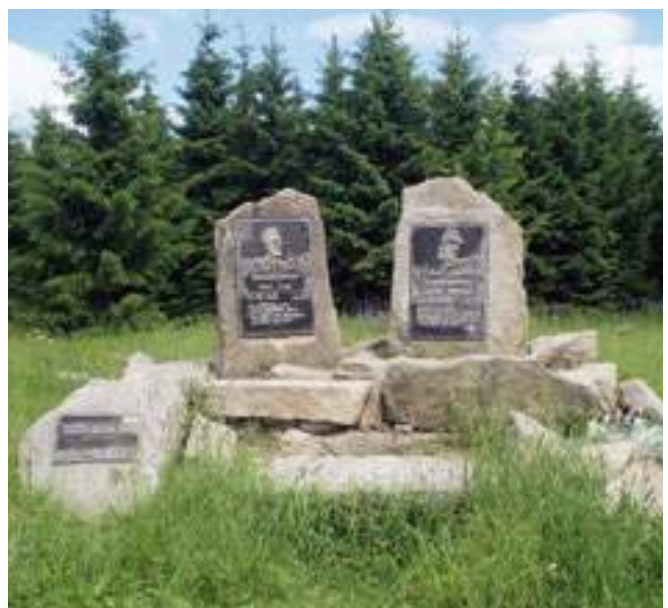

birger den vermeintlichen Verlust des Heimatgefühls. Günthers Vortragsart, eine Art erzählender Sprechgesang seiner einfachen Lieder mit schlichten Worten und gefälligen Weisen, begeisterte die Zuhörer. Es folgten erste Liedvorträge in der Prager Berufszeit, im multikulturellen Wien und in Gast- und Berghäusern des Erzgebirges. 1896 veröffentlichte er im Selbstverlag eine erste Liedpostkarte mit dem Lied „Drham is drham“, die zum Verkaufsschlager wurde und über hundert weitere Lieder auf Postkarten nach sich zog. Ab 1902 trat er vor allem im Erzgebirgsverein e. V. auf, was zu erhöhten Teilnehmerzahlen bei den sogenannten „Heimatabenden“ führte. Um 1907, als Günther u. a. in der Weltstadt Berlin seine Lieder vortrug, gehörten sie bereits zum Volksliedgut des Erzgebirges. Darüber hinaus präsentierte Günther seine Lieder in vielen Orten Sachsens und auch vor dem Protektor des Erzgebirgsvereins e. V., seiner Majestät König Friedrich August von Sachsen (18651932), und in deutschen Landsmannschaften, Sprach-, Literatur-, Gesangs- und volkskundlichen Vereinen. Schon bald wurden seine Lieder in der Öffentlichkeit vehement gefeiert und er als „Vater des Erzgebirges“ vergöttert: Er erhielt 51 Ehrenmitgliedschaften in Vereinen und 21 Ehren-bürgerschaften in meist erzgebirgischen Städten. Im Vorwort seines zweiten Heftes „Vergaß die Hamit net“ („Vergiß die Heimat nicht“) merkte Anton Günther 1921 an: „Das Leben ist ein Kampf und aus diesem Kampfe sind meine Lieder empor gewachsen. Ich kann kein Lied machen. [...] Ich hätte nie gedacht, daß meine einfachen Lieder so weit in die Welt hinaus dringen." ${ }^{4}$ Sprüche, Gedichte, Liedverse von Anton Günther, die ab 1903 in der „Glückauf“-Zeitschrift des Erzgebirgsvereins e. V. publiziert wurden, erwie-
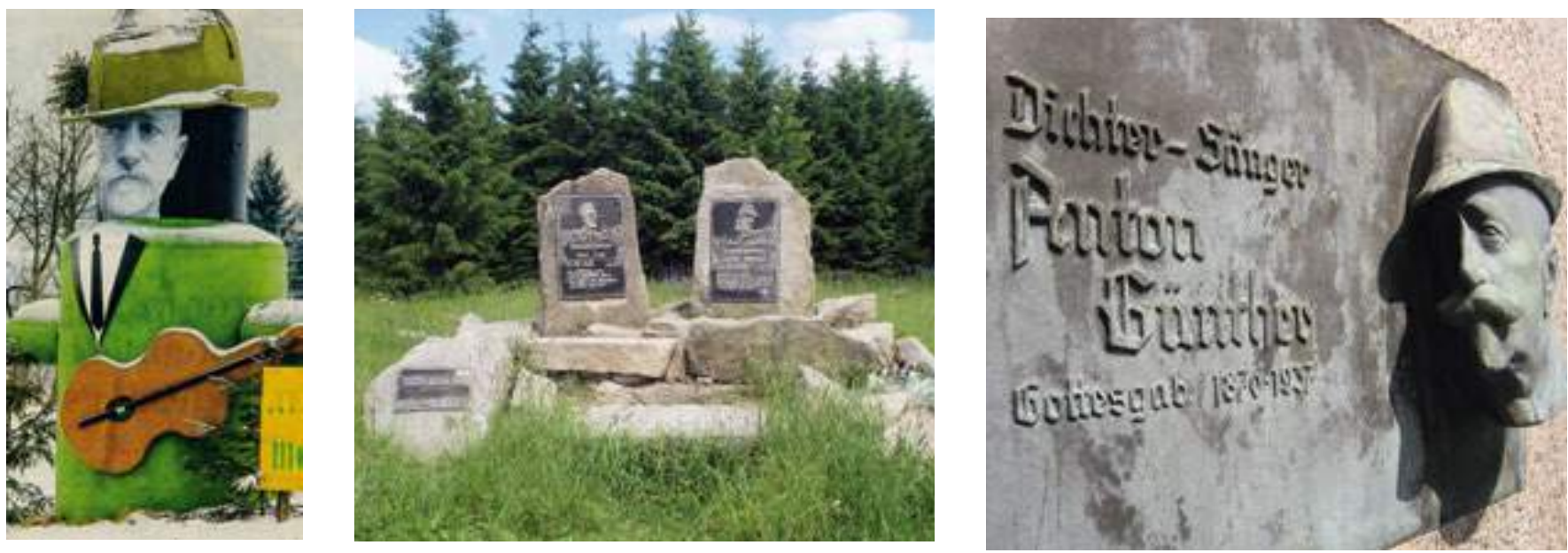
sen sich als geeignete Heimatwerbung in den Medien und der Öffentlichkeit. 1908 und 1942 erschienen zudem Hefte mit Anton-Günther-Liedern bearbeitet für Männerchöre. Diese Mundartlieder gehören bis heute zum Repertoire zahlreicher Chöre im Erzgebirge. Der Anton-Günther-Chor Seiffen e. V., entstanden aus einem 1847 gegründeten Männergesangsverein, erhielt 1997 zu seinem 150jährigen Jubiläum sogar die „Zelter-Plakette“.

$\mathrm{Zu}$ Günthers enormer Popularität trugen sicher die bereits ab 1921 aufgenommen Lieder auf Schellackplatten bei, die eine enorme Resonanz bei der erzgebirgischen Bevölkerung auslöste.

Mit zunehmender Beliebtheit der Lieder Anton Günthers und einer bis heute nicht abbrechenden kultartigen Verehrung seiner Person hat das erzgebirgische Mundartlied Generationen vieler Erzgebirger auf ihrem gesamten Lebensweg begleitet und wurde zur emotionalen Heimat. 1957 fand aus Anlass seines 20. Todestages in Boží Dar (Gottesgab) an seinem Grab eine Gedenkfeier statt. Erwin Günther (1909-1974), der Sohn Anton Günthers, führte das Erbe seines Vaters fort. Außerdem wurden zahlreiche Straßen, Plätze und Gasthäuser nach Anton Günther benannt, und man konnte Souvenirs unterschiedlichster Art (Schnitzereien, Bilder, Perlstickerei etc.) bis hin $\mathrm{zu}$ einer Gedenkmedaille aus Porzellan (1941) oder einem Briefbeschwerer mit Erinnerungsplakette erwerben. Zwischen 1917 und 2001 erwiesen mehr als 20 erzgebirgische Mundartautoren Anton Günther ihre Referenz in Erinnerungsgedichten und -liedern. Eine Vielzahl von musikwissenschaftlichen Forschungsarbeiten widmen sich Leben und Werk Anton Günthers. 1937, nach dem unfassbaren Suizid von Anton Günther, gründeten 42 Mundartdichter einen Anton-Günther-Dichterkreis. Über 45 Denkmäler und Gedenksteine wurden zwischen 1936 und 2013 aufgestellt und ein jährliches Sängertreffen am Grab in Boží Dar erinnert neben einem Anton-Günther-Wanderweg im sächsisch-böhmischen Erzgebirge (1995), einem Anton-Günther-Volksmusikfest (1996/1997) und vielen anderen Gedenkveranstaltungen an diesen Sohn des Erzgebirges. Bis heute kann man im Handel CDs mit Originalaufnahmen erwerben. 2010 erschien z. B. „Anton Günther Remixed“-CD von Robin Hermann, der damit Jugendlichen den Zugang zu Mundartliedern erleichtern möchte. Allerdings lebt auch der völkisch-nationale und
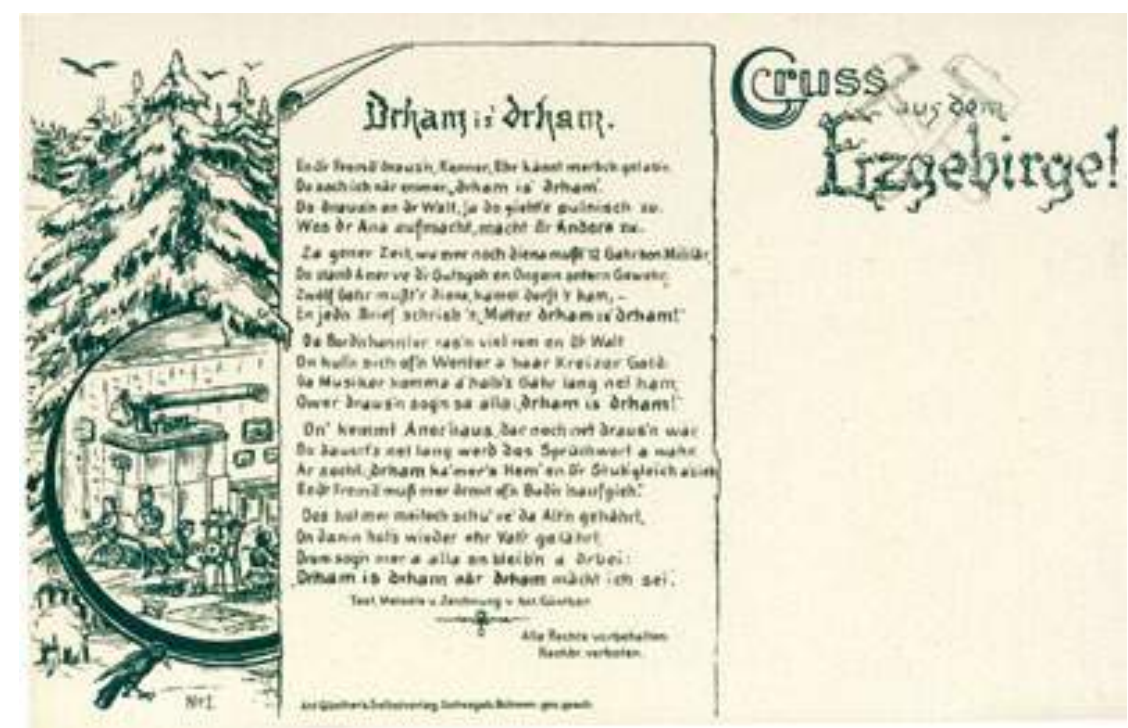

reaktionäre Unterton einer nationalsozialistischen Ära im Erzgebirge in der jüngsten Partei- und Wahlwerbung der NPD auf, die, wie seinerzeit die NSPD, für ihr Heimatverständnis 2013 Anton Günther als Identifikationsfigur benutzte. ${ }^{5}$

\section{Verbreitung durch Liedpostkarten}

Zur Verbreitung des erzgebirgischen Mundartliedes trugen in besonderer Weise die Liedpostkarten bei, auf denen meist ein Bild, der Liedtext und Noten abgebildet sind. Anton Günther verzichtete anfangs noch auf das Notenbild, druckte jedoch den Text aller Stro-

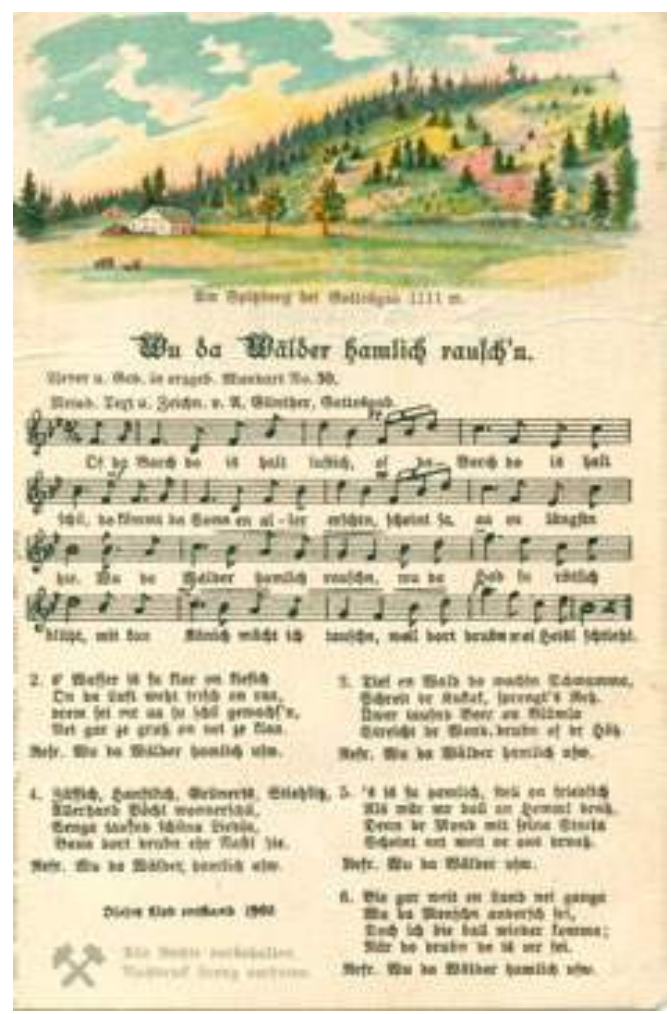

Erste Liedpostkarte von Anton Günther mit dem Text zu „Drham is drham" von 1895
4 Günther, Anton: Vergaß dei Hamit net! Lieder aus dem Erzgebirge, 2. Heft, Leipzig 1921, Vorwort S. III und VI.

5 Vgl. Wahlplakate zur Bundestagswahl 2013 und Kommunal- und Europawahl 2014. Dazu: Werner, Elvira: NPD-Wahlwerbung 2013 politisiert den Volksdichter Anton Günther (1876-1937) und seine erzgebirgische Identität - 500 Wahlplakate machen Anton Günther zum NPD-Wähler in: GlückaufZeitschrift des Erzgebirgsvereins e. V. 124 (2013), S. 171.

6 Unsere Heimatsänger treten an!, in: Tageblatt-Annaberger Wochenblatt $\mathrm{v}$. 14.08.1937; Heimann, W.: Der Sängerwettstreit aus dem Erzgebirge, in Tageblatt-Annaberger Wochenblatt vom 23.08.1937.

7 Graefe, Arthur: Volkstum und Heimat, in: Sachsen, Zeitschrift des Heimatwerkes Sachsen, Doppelheft 2-3, Dresden 1941, S. 47-48.

Liedpostkarte von Anton Günther mit Text und Noten, um 1910 
Adventsveranstaltung in
Scheibenberg mit Albert Schädlich,
Anton Günther, Curt Herbert
Richter sowie Max Rothe mit
seiner Heimatgruppe "Rothe
Mäd", Klöpplerinnen, den Lehrern
Meyer und Schönherr und dem
Rundfunkmoderator Josef Krahe (2. von rechts), 1932

8 Stapff, Helmut: Mei Arzgebirg, wie bist du schie, 20 Lieder aus dem singenden Erzgebirge, Dreistimmig für Kinder oder Frauenchor bearbeitet von R. WagnerBuchholz, Leipzig 1937, 2. Folge 1938, vgl. Vorworte; Werner 1999, wie Anm. 70, S. 101.

9 Henschel 1939, wie Anm. 29, Vorwort S. V-VI; Horst Henschel war Referent für erzgebirgische Mundart und Mundartschrifttum im Heimatwerk Sachsen e. V.

10 Curt-Herbert Richter an Heimatfreud Werner Unger, Schneeberg, Brief v. 22.10.1957 phen ab. Nach neueren Sammlerrecherchen sind 136 in Liedheften und mindestens $88 \mathrm{Ti}-$ tel in verschiedenen Varianten auf einer nicht genau zu erfassende Anzahl von Liedpostkarten veröffentlicht worden. Seine anfangs im Selbstverlag und ab 1920 im Vertrieb des Kunstverlages Wilhelm Vogel herausgegebenen Liedpostkarten fanden als Spezifikum der erzgebirgischen Liedpflege reichlich Nachahmung und trugen bis ins Vogtland zur Popularisierung dieser Liedgattung bei. Zwischen 1898 bis in die 1950er Jahre verlegte Wilhelm Arthur Vogel (1868-1962) ca. 70 Lieder weiterer Mundartautoren. Neben einigen Neuerscheinungen in den 1950er Jahren und nach einer kleinen Wiederauflage ab den 1980er Jahren sind traditionelle Liedpostkarten ein beliebtes Erinnerungs- wie Sammelobjekt, wobei sie im Fall von Anton Günther hohe Versteigerungssummen erzielen können.

\section{Chöre, Gesangs- und Instrumentalgruppen}

Die Begeisterung für das erzgebirgische Mundartlied zeigte sich bereits im Repertoire der frühen Männergesangsvereinigungen und gehört bis heute in den regionalen Chören dazu. Sie führte vor allem zur Gründung erster, mehrstimmiger Mädchengesangsgruppen, was erwähnenswert erscheint. 1923 gründete sich beispielsweise das „(Zschorlauer) Albert-Hänig-Quartett“, welches sich 1931/32 in „Zschorlauer Nachtigallen“ umbenannte. Sie waren gefragt zu zahlreichen Vereinsveranstaltungen, Sängertreffen, Ausstellungen, Volkstums- und Heimatabenden, Volkskundetagungen in ganz Sachsen, darüber hinaus mit Einsätzen zu Tagen der Erzgebirger in Berlin 1935, 1937 in Schwarzenberg und späterhin an der Front. Mundartdichter widmeten den „Nachtigallen“ Gedichte.

Die 1927 vom Oberlehrer Max Rothe gegründete Singgruppe „Rothe-Mäd“ wirkte am 3. Dezember 1932 zum Musikfest in Annaberg in einer ersten vom Mitteldeutschen Sender übertragenen, öffentlichen Adventsveranstaltung mit und reiste als „Propagandist“ der Heimat 1937 zum Trachtenfest nach Bayreuth. In der DDR erhielt diese Gruppe mehrfach Auszeichnungen. In der Rundfunkübertragung vom 3. Dezember 1932 nahmen außerdem Anton Günther, der Zither-Solist Curt-Herbert Richter, der Mundartdichter Albert Schädlich und Mitglieder aus der „Oberscheibner Klippelschul" teil.

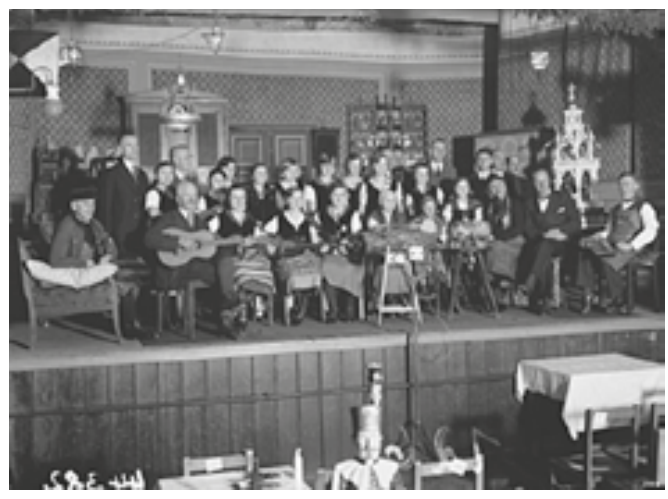

Das erzgebirgische Mundartlied im Nationalsozialismus

Dem Heimatwerk Sachsen - Verein zur Förderung des sächsischen Volkstums e.V. (1936 bis 1945) oblag als Dachorganisation und fest eingebunden in die Strukturen von nationalsozialistischer Partei- und Staatspolitik „die zentrale Steuerung regionalkultureller Bestrebungen“. Er sollte als „Vorfeldorganisation der sächsischen NSDAP [...] auch Nicht-Parteimitglieder über ein spezifisches regionales Identifikationsangebot für das Dritte Reich mobilisieren“. Das Heimatwerk war dabei vor Ort auf Kooperationspartner angewiesen und so kam es während der NS-Zeit letztlich zu einer gewissen „wahllosen Förderung aller regionalkulturellen Aktivitäten“. In den meisten Vereinen dominierte eine unpolitische Heimatverbundenheit. Die Volkskunst im Erzgebirge nahm innerhalb der nationalsozialistischen Volkstumspflege schon bald eine Vorreiterrolle ein. Vor allem Friedrich Emil Krauß (1895-1977) agierte in seiner Funktion als Vorsitzender des Heimatwerk-Sachsen e. V. als Förderer der erzgebirgischen Volkskunst. Der erzgebirgischer Unternehmer (Krausswerke) war von der WandervogelBewegung geprägt worden und ab 1934 oblag ihm auch die Funktion des Schwarzenberger Kreiskulturwarts der NSDAP. 1937 war er auf der Volkskundetagung in Dresden zum Vorsitzenden des Sächsischen Volksliederausschusses berufen worden. Er schrieb selbst mehrere Mundartgedichte, die vertont wurden. $\mathrm{Zu}$ den bekanntesten zählen bis heute „Dr Himmel is e Lichterbugn“ („Der Himmel ist ein Lichterbogen“), „In dr Hammerschenk zer Tanzmusik“ und „De Steigerkirmes“.

Das Heimatwerk förderte die Pflege der erzgebirgischen Mundartlieder „als ein klingendes Bekenntnis zu Heimat, Führer und Volk“6 und veranstaltete zwischen 1937 und 1944 sechsmal ein sogenanntes „Erzgebirgisches 
Streitsingen“, welches im Rundfunk übertragen wurde. Mundartpflege und erzgebirgisches Mundartlied erfuhren damit eine breite öffentliche Wahrnehmung, die $u$. a. die Zahl der teilnehmenden Gruppen wie auch die Bildung von Nachwuchsgruppen rasch ansteigen ließ. 1937 errangen die „Zschorlauer Nachtigallen" unter den 74 Solisten und Singegruppen einen ersten Platz. 1941 gelangten von 102 Gruppen als Auszeichnung 30 in die Endrunde des Streitsingens in Chemnitz. ${ }^{7}$

Regionale und überregionale Veranstaltungsangebote, Schellackplattenaufnahmen, Kulturfilme über das Erzgebirge und Rundfunkübertragungen stellten das Mundartlied als ein Image der Heimat in den Fokus. In überregionalen Begegnungen wie z. B. 1937 zur Gaukulturwoche in Elbefeld oder 1939 zum Reichswettstreit der deutschen Mundartdichter in Wuppertal galt die präsentierte Mundartpflege aus Sachsen als maßstabsetzend. 1937 gab Helmuth Stapff (1901-1978) zwei Liederhefte mit Liedern von Anton Günther u. a. Mundartdichtern heraus, um zu zeigen ,[...] wie sich diese Heimatliebe zur echten und tiefen Vaterlandsliebe weitet."8 Die musikalischen Bearbeitungen hatte Kirchenmusikdirektor Richard Wagner (18711950) aus Buchholz vorgenommen. Auch der Dresdner Kreuzkantor Rudolf Mauersberger (1889-1971), selbst Erzgebirger, führte aus Heimatverbundenheit 1936 die erzgebirgische Christmettentradition in Dresden ein. 1939 erschien im Auftrag des Heimatwerkes unter dem Titel „Singendes Land“ eine der Volksforschung dienende Sammlung von 400 erzgebirgischen Mundartliedern. Zusätzlich zu den Liedtexten (ohne Noten) sind Kurzvitas der 85 ausgewählten Mundart-Autoren und Vertoner sowie Anhänge verschiedenster Notenausgaben ausgewiesen. Mit dem Verkauf dieser Liedsammlung sollte $\mathrm{u}$. a. ein „Unterstützungsfonds für die erzgebirgischen Mundartdichter" ins Leben gerufen werden. Werner Vogelsang (1895-1945), Ortsgruppen- und Kreisleiter der NSDAP in Annaberg, Volkstumsbeauftragter für das Erzgebirge und ab 1937 neugewählter Vorsitzender des Erzgebirgsvereins schrieb im Geleit: „Das Lied ist ein Kernstück unseres Volkstums. Es begleitet den Erzgebirger durch sein ganzes Leben. Deshalb ist das Mundartlied eine Quelle zur Erkenntnis der Wesenszüge des Erzgebirgers. Seine Liebe zur Natur, zum Wald und seinen Tieren, die Verbundenheit mit seinem Alltag, sein Feierabend, also seine tiefe Liebe zu allem, was ihm Heimat ist, wird im Heimatlied noch einmal lebendig.“ 9

\section{Frühe Aufnahmen und Rundfunk- sendungen}

Dirk Gebhardt erstellte eine Auflistung zu den ersten Schellack-Aufnahmen erzgebirgischer Volkslieder. Die erste Orchesteraufnahme entstand um 1907 mit dem „Vugelbeerbaam“ („Vogelbeerbaum“). 1911 sangen die Leipziger Kristallpalastsänger AntonGünther-Lieder und 1913 kam es zu Aufnahmen des Zwickauer Mundartdichters Reinhold Fischer. Ab 1921 erfolgten Aufnahmen mit Anton Günther, Max Wenzel und Hans Soph. In den 1930er Jahren entstanden zunehmend Aufnahmen mit ersten Gesangsund Instrumentalgruppen u. a. vom „Erzgebirgischen Heimatabend“ in der Krolloper Berlin während der Tage der Erzgebirger am 28./29. September 1935. Es folgten spezielle Rundfunk-Sendungen wie z. B. „Volksmusik, gesungen vom Gesangverein“ in der $\mathrm{u}$. a. 1939 die „Zschorlauer Nachtigallen“ auftraten, und man machte Mitschnitte der „Erzgebirgischen Streitsingen“. Zusätzlich veröffentlichte man innerhalb der HeimatwerkVolkstumsförderung Aufnahmen mit Mundartliedern der Mundartvolkstumsbezirke auf Industrieschallplatten. Darüber hinaus kamen Solisten und Mundartgruppen wie z. B. die „Buchholzer Mäd“ auch in sächsischen Kulturfilmen und während des Zweiten Weltkrieges als Botschafter der „Heimatfront" an der Front zum Einsatz. Außerdem konzipierte man Mundartlieder als Frontlieder, wie z.B. F. E. Krauß, der einige Lieder in den 1940er Jahren in der Feldpostzeitung „Sachsenpost“ veröffentlichte.

\section{Das erzgebirgische Mundartlied in der DDR}

Nach dem Zweiten Weltkrieg beteiligten sich erzgebirgische Sänger mit Spenden am Wiederaufbau zerstörter Städte und Orte. Beispielsweise spendeten 1946/47 die „StapffGruppe“ und der Zither-Solist Curt-Herbert Richter (1898-1974) 100.000 Mark von ihrer Gage aus 125 Erzgebirgsabenden an den Aufbaufonds für das zerstörte Dresden. Aus Briefen im Richter-Nachlass geht allerdings hervor, dass Helmut Stapff (1901-1978) seinerzeit mit großen Unterschieden in der Gagenberechnung die Existenz von Richter und seiner Familie gefährdet hatte. In den 1950er Jahren verzog Stapff nach Westdeutschland. ${ }^{10}$

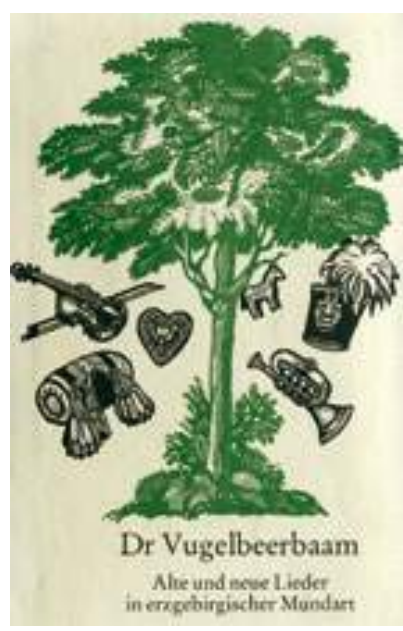

Liedersammlung „Dr Vugelbeerbaam" ("Der Vogelbeerbaum") von Manfred Blechschmidt, Leipzig 1970.

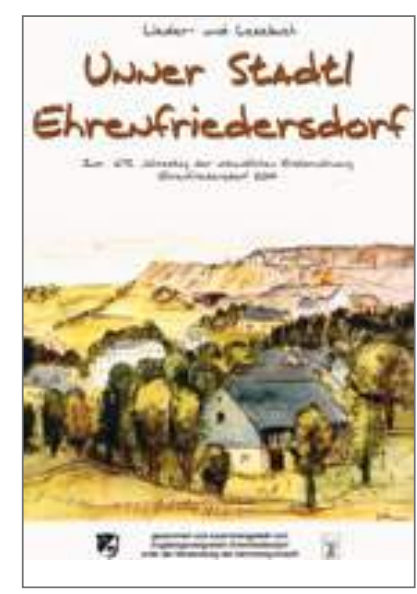

Publikation mit Mundartliedern zum 675. Jahrestag der urkundlichen Ersterwähnung von Ehrenfriedersdorf, 2014 


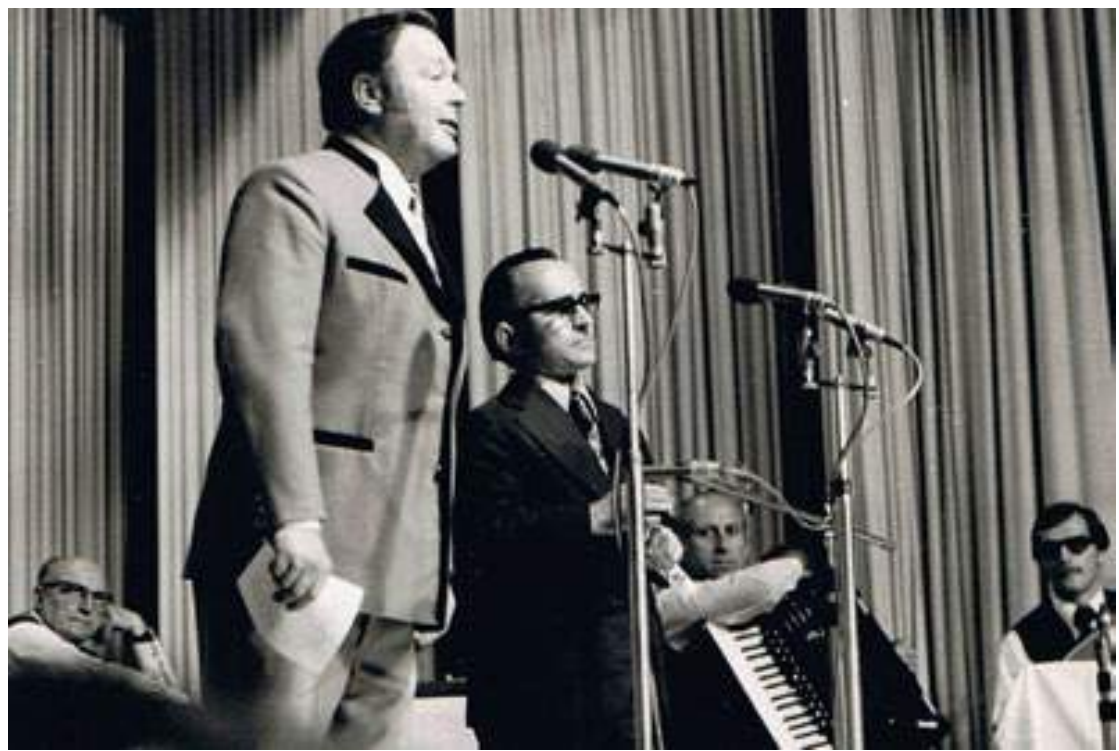

Die Sänger Horst Gläß mit Werner Kempf aus dem "Erzgebirgsensemble Aue" während eines Konzerts in den 1960 er Jahren. Foto: Archiv Erzgebirgsensemble.
Schon in den örtlichen Nachkriegsveranstaltungen und verstärkt seit den 1950er Jahren waren die Akteure der Mundartpflege, insbesondere auch Zither-Solisten (Curt Herbert Richter, Willi Kaltofen, Joachim Süß und Hans Eder) im Erzgebirge sehr gefragt. Bisherige Gruppen wurden fortgeführt, wiederbelebt oder neue gegründet. Ab 1946 erklangen erzgebirgische Mundartlieder erneut in Rundfunksendungen. Dazu gehörten $u$. a. der Zither-Solist Curt Herbert Richter mit seinem Instrumentaltrio und „Sawall-Terzett“ und bekannte Gruppen wie die „Geschwister Calderelli“ oder die „Helmut-Stapff-Gruppe“. Richter begründete mit Georg Baumann 1946 die sogenannte „Leipziger Volksmusikstunde“ des Mitteldeutschen Rundfunks, die im Laufe der Jahre weit über die Grenzen Deutschlands hinaus bekannt wurde. Nach der Auflösung und Eingliederung des Mitteldeutschen Rundfunks in das Staatliche Rundfunkkomitee der DDR 1952 wurde diese Volksmusikstunde eingestellt. Richter hatte als ständiger Mitarbeiter an mehr als 150 Sendungen mitgewirkt.

Erzgebirgische Mundart- und Musikpflege erlangte erneut in den 1950/1960er Jahren neben ihren zahlreichen regionalen Veranstaltungen der „Erzgebirgs- und Heimatabende“ mit den DDR-weiten Tourneeprogrammen überregionale Bekanntheit und Beliebtheit. Verstärkt seit den 1970er Jahren erklangen Mundartlieder in regelmäßigen Rundfunksendungen wie z. B. „Volkskünstler singen und musizieren“, „Erlebte Heimat DDR oder Volkstümliche Klänge zur Abendstunde“, „Typisch Sachsen“, „Spitzenparade der volkstümlichen Weisen“ und im DDRFernsehen. Die Sendungen fanden nach der deutschen Wiedervereinigung mit der „Volkstümlichen Hitparade“ im Rundfunk eine eingeschränkte und in den Fernsehsendungen wie „Musikanten sind da“, „Alles singt unterm Tannenbaum“, „Su klingt's bei uns im Arzgebirg“ oder der „Wernesgrüner Musikantenschenke“ ihre Fortsetzung.

Dass sich das erzgebirgische Mundartlied als eine stabile kulturpolitische Komponente im volkskünstlerischen Laienschaffen der DDR behaupten und entwickeln konnte, ist eng mit dem ununterbrochenen Wirkungspotenzial erzgebirgischer Solisten, Gesangs- und Instrumentalgruppen, aber auch mit der Person von Manfred Blechschmidt (1923-2015) und seinem Erzgebirgsensemble Aue verbunden. Blechschmidt, der selbst als Kind die „Streitsingen“ miterlebt hatte, publizierte ab 1960 ausgehend von erzgebirgischer Mundartdichtung ein umfangreiches Lebenswerk auch regionalgeschichtlicher Literatur und das erzgebirgische Mundartlied betreffende Beiträge im Jahrbuch des Volksliedarchivs Freiburg. Unerschöpflich ist die Vielfalt seiner in der DDR-Zeit mehrfach ausgezeichneten Verdienste als Revierförster, Fachbuchautor, Volksschuldirektor, Pädagoge, Schriftsteller, Lektor, Chronist, Heimatforscher, kulturpolitischer Funktionär (SED/ Kulturbund) und Förderer von Regionalkultur, nicht zuletzt als Gründer des erfolgreichen und international anerkannten Erzgebirgsensembles Aue, das er bis 1988 führte und das in seinen traditionellen Bühnenprogrammen (Mundart-) Wort, Lied, Musik und Tanz vereint. Das bis heute gerade auch in der Nachwuchsarbeit so aktive Erzgebirgsensembles Aue war seit jeher in seiner professionell ausgerichteten künstlerischen Qualität, Nachwuchs- und Forschungsarbeit Maßstab und Ansporn für Förderer und Akteure der Mundartpflege.

Zwischen 1966 und 1988 fanden 17-Mal die beliebten sogenannten „Kuchensingen“ statt. Ab 1979/80 führte man Bezirksleistungsvergleiche und Workshops für erzgebirgische und vogtländische Gesangs- und Instrumentalgruppen ein. Eine in den 1960er Jahren gegründete Bezirksarbeitsgemeinschaft für Instrumentalmusik in Karl-Marx-Stadt unterstützte die Kulturarbeit u. a. mit Lehrgängen für Leiter aus dem Volkskunstschaffen und mit Liedheften und Liedpostkarten für das Vogtland und das Erzgebirge. „Tage der erzgebirgischen bzw. vogtländischen Folklore“ (1979-1989) bzw. die „Tage erzgebirgischer Folklore“ in der Stadthalle Karl-Marx-Stadt (heute Chemnitz) gehörten zu den Höhe- 
punkten der zahlreichen Veranstaltungen. Ein Desiderat bis zur deutschen Wiedervereinigung blieben die fast aussichtslosen Veröffentlichungsmöglichkeiten von Tonträgerproduktionen. Jahrzehntelange Defizite an Tonträgern für das erzgebirgische Mundartlied konnten hier insbesondere von B.T.M. $\mathrm{GmbH}$ Musikproduktion Berlin und der Saxonia Tonträgerproduktion Plauen nicht ersetzt aber weitestgehend ausgeglichen werden.

Während der DDR-Zeit entstanden oftmals ausgerichtet an einem propagierten zeitgemäßen „sozialistischen Heimatbegriff“ neue Mundartlieder unterschiedlicher Gebrauchsqualität. Sie sollten in den 1950/60er als übergreifendes nationales Konstrukt fungieren (,neue Zukunft, neuer Mensch, neues Lebensgefühl“, Parteinahme für die Heimat von heute) oder wirtschafts-, kultur- und sozialgeschichtliche Umbrüche wie sie mit dem Wismutbergbau (1946-1990) im Erzgebirge verbunden waren, widerspiegeln. Dazu zählt beispielsweise in den 1950er Jahren im Annaberger Raum das Bergbauund Kumpellied. Nur ein Teil dieser neuen Mundartlieder gehört bis heute zum Repertoire, wie z. B. das mit der Gründungsgeschichte des Erzgebirgsensembles Aue verbundene „De Mad, die bracht en Freier ham“ („Die Magd, die brachte einen Freier heim“) von Blechschmidt und aus dem Jahr 1962 „Kuchnsinge“ von Blechschmidt und Helmut Merkel (1915-1982) oder auch das so sinnige und beliebte „In jeden Baam do hängt e Lied“ von Gläß und Steinz. Vielen dieser der neuen Zeit verpflichtenden „Auftragswerke" fehlte jedoch der künstlerische Anspruch und Poesie. Doch gerade die Werke von Blechschmidt und Merkel sind von bleibender Bedeutung. Seit 1966 bis zu seinem Tod wirkte Merkel, ein der Volksmusik mit Herz und Verstand verbundener Komponist (500 Kompositionen) und Musiker, erfolgreich als musikalischer Leiter im Ensemble. Zahlreiche Langspielplatten (VEB Deutsche Schallplatten Berlin, Label Eterna) belegen dies. Anton Günthers „Deitsch on frei wolln mer sei“ („Deutsch und frei wollen wir sein“) von 1908 fehlte darauf: Es war zu DDR-Zeiten oftmals in Unkenntnis seiner frühen Entstehungsgeschichte (Studentenlied) und aufgrund seines Missbrauchs in der nationalsozialistischen Zeit als „erzgebirgisches Bekenntnislied“ offiziell unerwünscht. Ein Umstand, der oftmals auf die Bewertung des Autors und seine weiteren Lieder übertra- gen wurde. Doch seit Mitte der 1970er Jahre sang man diese wieder verstärkt - und selbst SED-Funktionäre in ihrer Privatsphäre. ${ }^{11}$ „Deitsch on frei..." kam in der Zeit der politischen Wende (Montagsdemonstrationen) und mit der Neugründung des Erzgebirgsvereins e. V. in seinen Veranstaltungen ganz bewusst zum Einsatz; mittlerweile ist es wieder stiller um dieses Lied geworden. Mit der politischen Wende erfuhr das tradierte erzgebirgische Mundartlied im innovativen Kulturalltag Aufbruch und Wandlung. Akteure, die meist auf hohe Jubiläen ihres Schaffens zurückblicken (u. a. „BingeMaad“, „Erzgebirgsgruppe Ehrenfriedersdorf“, „Schennhaader Maad“, „Zwickauer Kohlmeisen“, „Heimatgruppe Krumhermersdorf“, „Heimatspiegel Zschorlau“), erlangen trotz anfänglicher Einbrüche der Förderung und Auftrittsgelegenheiten eine verstärkte Wahrnehmung nicht zuletzt über Mitglieder aus dem Erzgebirgsverein. Mit einer expandierenden öffentlichen Festkultur, wie den zahlreichen Orts- und Heimatfesten, entstanden in den 1990er Jahren verstärkt neue Heimat- und Ortslieder. Alltagsstimmungen, von Wende und Globalisierung gezeichnete Geschichten vor Ort fließen in neue Texte ein.

\section{Erfassung und Bewahrung}

Das Internet und insbesondere Wikipedia ermöglichten die Erfassung der Hauptvertreter der erzgebirgischen Mundartpflege und ihres Wirkens. Aber dennoch bleiben das detaillierte Erfassen und Dokumentieren aller in ost- und westerzgebirgischer Mundart verfassten Lieder und ihrer Varianten in einer Publikation oder Online-Datenbank ein wichtiges und sicher lohnenswertes Vorhaben. Auftakt dazu bot schon 1939 die Publikation „Singendes Land. 400 Mundartlieder aus dem Erzgebirge“. Inspiriert durch eine Mundarttagung im Jahr 1999 begann Familie Knauth aus Ehrenfriedersdorf umfangreiche Sammlungsaktivitäten zum erzgebirgischen Liedgut mit Blick auf bekannte und unbekannte Nachlässe und Sammlungen. Der bisherige Sammlungsbestand umfasst 146 Komponisten und 1.649 Lieder. In den 1980er Jahren beliefen sich Schätzungen auf eine Anzahl von ca. 1.700 Liedern, die um einen nicht geringen, möglicherweise mehrfachen Bestand gewachsen sein dürfte. Das Vorhaben einer solchen Gesamt-Erfassung wäre sicher ein lohnenswertes, längerfristiges Projekt.

Glückauf Erzgebirge!

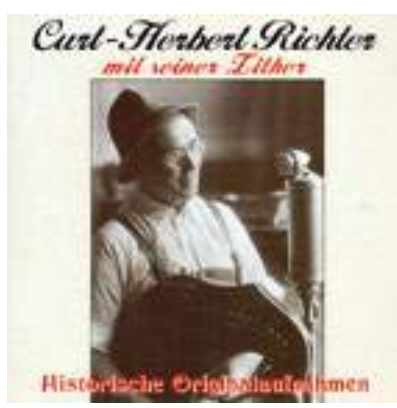

CD-Cover aus den 1990er Jahren mit historischen Aufnahmen von Curt Werner Richter

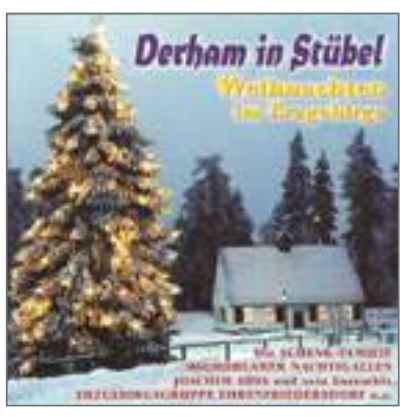

Typisches CD-Cover einer erzgebirgischen Weihnachts-CD aus den 1990er Jahren

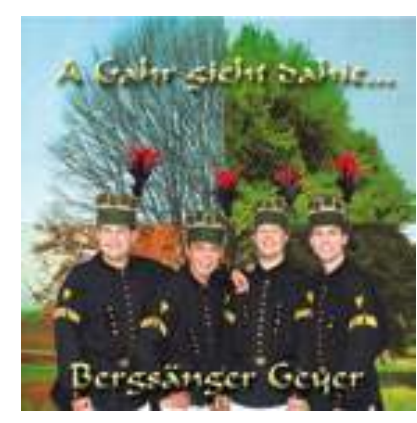

CD-Cover der „Bergsänger Geyer", 2006

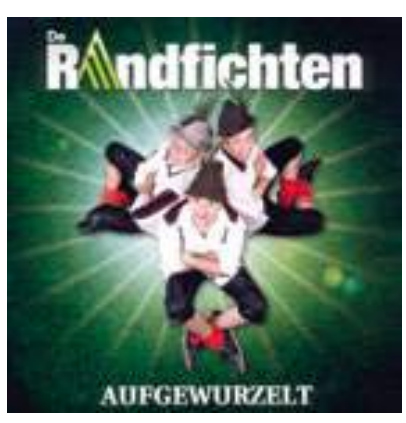

Cd-Cover des Albums „Aufgewurzelt" von den "Randfichten", 2012.

\section{Autorin}

Elvira Werner

Schwarzenberg 


\section{Weiterführende Literatur (Auswahl):}

Albrecht, Helmuth: Die Montanregion Erzgebirge als Industrie-Kulturlandschaft, in: Sächsische Bergbauregionen im Wandel. Reflexionen, Positionen, Perspektiven im 20./ 21. Jahrhundert, Chemnitz 2008.

Bachmann, Manfred: Zum sozialistischen Heimatbegriff, in: Sächsische Heimatblätter, 9 (1963), S. 1-6.

Bartella, Petra: Mir sei halt mir. 40 Jahre Heimatspiegel - eine kleine Rezension, Zschorlau 2013.

Beer, Mathias: Das Heimatbuch. Geschichte, Methodik, Wirkung, Göttingen 2010.

Blaschke, Karlheinz: Landesgeschichte im Überblick, in: Auf den Spuren der musikalischen Volkskultur im Erzgebirge, München 2009.

Blechschmidt, Manfred: August Schreyer und das Lied vom Vogelbeerbaam, in: Brednich, Rolf Wilhelm (Hrsg.): Jahrbuch für Volksliedforschung 27 (1981), S. 100-105.

Blechschmidt, Manfred/Barthel, Friedrich (Hrsg.): Stimmen der Heimat. Dichtungen in erzgebirgischer und vogtländischer Mundart von den Anfängen bis zur Gegenwart, Leipzig 1960.

Blechschmidt, Manfred: Die Liedpostkarte in der erzgebirgischen und vogtländischen $\mathrm{Mu}-$ sikfolklore, in: Jahrbuch für Volksliedforschung 26. (1980), S. 98-105.

Blechschmidt, Manfred: Die Russischen Hörner in der Musikfolklore des sächsischen Erzbergbaus, in: Sächsische Heimatblätter 20 (1974), S. 270-274.

Buchholz, Kai: Begriffliche Leitmotive der Lebensreform, in: Die Lebensreform. Bd. 1, Darmstadt 2001.

Diebner, Bernd J./ Lehr, Rudolf (Hrsg.): Deutsche Mundarten an der Wende? Will dich festhalten ..., Heidelberg 1995.

Ditt, Karl: Die deutsche Heimatbewegung (1871-1945), in: Heimat. Analysen, Themen, Perspektiven, Bonn 1990.
Eckardt, Günther: Der Erzgebirgsverein e. V. und das regional-kulturelle Erbe in Vergangenheit und Gegenwart, unveröffentlichte Diplomarbeit Universität Leipzig, Leipzig 1989.

Faehndrich, Jutta: Entstehung und Aufstieg des Heimatbuches, in: Beer, Mathias (Hrsg.): Das Heimatbuch. Geschichte, Methodik, Wirkung, Göttingen 2010.

Firmenich-Richartz, Johann Matthias: Germaniens Völkerstimmen. Sammlung der deutschen Mundarten in Dichtungen, Sagen, Märchen, Volksliedern, Berlin 1854.

Fröbe, Walter: Erzgebirgische Mundart und erzgebirgische Mundartdichtung, in: Glückauf, Zeitschrift des Erzgebirgsvereins e. V. 49 (1929), S. 66.

Gebhardt, Dirk: Chronologie der SchellackAufnahmen mit erzgebirgischen Volksliedern, Entwurfsmanuskript 2005.

Gebhardt, Dirk: Discographie der Schellackplatten mit erzgebirgischen Aufnahmen, in: Krüger, Klaus (Hrsg.): Die Deutsche National-Discographie, Serie 1, Discographie der deutschen Kleinkunst, Band 5, Bonn 1998.

Gläß, Horst: In jeden Baam do hängt e Lied. Gedichte, Geschichten und Lieder von Horst Gläß, illustriert und zusammengestellt von Dieter Böttger, Stollberg 1991.

Gleißner, Käthe: Der Stand der Mundartforschung in Sachsen, in: Mitteldeutsche Blätter für Volkskunde 11 (1936), S. 145-151.

Greverus, Ina-Maria: Auf der Suche nach Heimat, München 1979.

Greverus, Ina-Maria: Der territoriale Mensch. Ein literaturanthropologischer Versuch zum Heimatphänomen, Frankfurt am Main 1972.

Günther, Manfred/Walther, Lutz: Anton Günther. Freiheit zwischen Grenzen. Die Biographie, Friedrichsthal 2011.

Heilfurth, Gerhard (Hrsg.): Anton Günther. Gesamtausgabe der Liedtexte, Gedichte, Sprüche und Erzählungen, Schwarzenberg 1937.

Heilfurth, Gerhard (Hrsg.): Der erzgebirgische Volkssänger Anton Günther: Leben und Werk, Leipzig 1994. 
Heilfurth, Gerhard: Einzelzüge im geschichtlich-kulturellen Antlitz des Erzgebirges mit Ausblicken auf sein Umfeld. Beiträge zur Erkundung einer regionalen Lebenswelt im ostmitteleuropäischen Grenzbereich, Marburg 1989.

Hengst, Karlheinz: Hutzen - wie kam es zustande?, in: Erzgebirgische Heimatblätter 6/2007, S. 14-16.

Herrmann, Lothar/Fickel, Rolf: Curt-Herbert Richter „Musik - mein ganzes Leben“. Skizzen eines Musikerlebens, Bernsbach 1993.

Heydel, Fred: Das Hans-Soph-Buch. Leben und Werk des Erzgebirgssängers, Leipzig 1955.

Kaden, Werner: Musikkultur im Erzgebirge, Schneeberg und Chemnitz 2001.

Leitner, Hartmut: Eine Erinnerung an Anton Günther, in: Erzgebirgische Heimatblätter $2 / 2004$.

Leonhardt, Werner: Die Bedeutung der Mundartgruppen in der Brauchtumspflege des Erzgebirges - dargestellt am Beispiel der „Zschorlauer Nachtigallen“, unveröffentlichtes Manuskript, Zschorlau 1991.

Leopold Christine: Leben und Werk Anton Günthers, unveröffentlichtes Manuskript, Pädagogisches Institut Zwickau, Zwickau 1969.

Möckel, Hermann: Ehrung für den Volksdichter Anton Günther in Gottesgab, in: Glückauf-Zeitschrift des Erzgebirgsvereins e. V. 1908, S. $122-123$.

Müller, Emil: Mehr Interesse für unsere Mundart-Literatur, in: Glückauf, Zeitschrift des Erzgebirgsvereins e. V. 36 (1916), Heft 4, S. 58-59.

Reuschel, Karl: Der Gefühlsausdruck im erzgebirgischen Volksliede, Vortrag auf der Hauptversammlung des Vereins für Sächsische Volkskunde am 7. September 1913, in: Dresdner Anzeiger, Bd. 14, Dresden 1924, S. 174-175.

Ruhheim, Karl (Pseudonym für Christian Gottlob Wild): Reise durch das sächsische Erzgebirge, Leipzig 1805.
Schaarschmidt, Thomas: Vom völkischen Mythos zum „sozialistischen Patriotismus“, Sächsische Regionalkultur im Dritten Reich und in der SBZ/DDR, in: Diktaturvergleich als Herausforderung. Theorie und Praxis, hrsg. von Günther Heydemann u. Eckhard Jesse, Berlin 1998.

Schaarschmidt, Thomas: Regionalkultur und Diktatur. Sächsische Heimatbewegung und Heimat-Propaganda im Dritten Reich und in der SBZ/DDR, Köln/Weimar/Wien 2004.

Schlegel, Gerhard u. a.: 125 Jahre Erzgebirgsverein, Festschrift, Marienberg 2003.

Schmitz, Walter: Die Zeichen der „Heimat“. Zur Semiotik eines wandelbaren Konzeptes in der deutschen Kultur, in: Klose, Joachim (Hrsg.): Heimatschichten, Wiesbaden 2013.

Seibt, Hendrik: Anton Günther. Ein Liedermacher aus dem Erzgebirge, unveröffentlichtes Manuskript, Hochschule für Musik Franz Liszt Weimar, Weimar 1994.

Teller, Christian: Christian Gottlob Wild zum 200. Geburtstag, in: Sächsische Heimatblätter, 5/1986, S. 229-233.

Werner, Elvira: Das Erbe Anton Günthers. Zur Rezeption seines Werkes, in: Sächsische Heimatblätter 41 (1995), S. 224-236.

Werner, Elvira: Mundart im Erzgebirge, Marienberg 1999.

Werner, Elvira: Krippenspiele im sächsischen Erzgebirge, in: Seifert, Manfred/Bröcker, Marianne (Hrsg.): Aspekte des Religiösen in popularen Musikkulturen, Dresden 2010.

Werner, Elvira: „Heimatbuch“ - Welche literarischen Spuren hinterließ der WismutBergbau in der Regionalkultur?, in: Ette, Wolfram u. a. (Hrsg.): Strahlungen. Literatur um die Wismut, Würzburg 2012.

Wirr, Andreas (Hrsg.): Sprachverfall?, Berlin/Boston 2014.

Zirkler, Albert: Mundart und Schriftsprache, in: Meier, John: Lehrproben zur deutschen Volkskunde, Berlin und Leipzig 1928, S. 99-113. 